\title{
Intense laser infrastructures
}

\author{
François Amiranoff
}

Laboratoire d'Utilisation des Lasers Intenses - Palaiseau - France 


\title{
Intense laser infrastructures
}

\author{
F. Amiranoff \\ Laboratoire d'Utilisation des Lasers Intenses
}

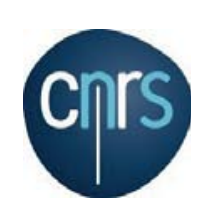

cea

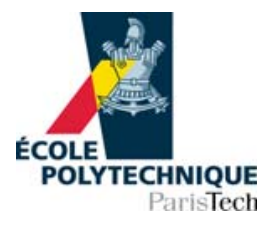

UPMC 
A very high power focused into tiny spots to produce hot and dense matter and intense fields

Target heated up to millions of degrees keV - MeV

High-power laser beam

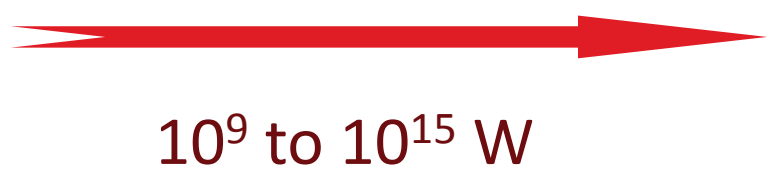

Intensities $10^{13}-10^{20} \mathrm{~W} / \mathrm{cm}^{2}$

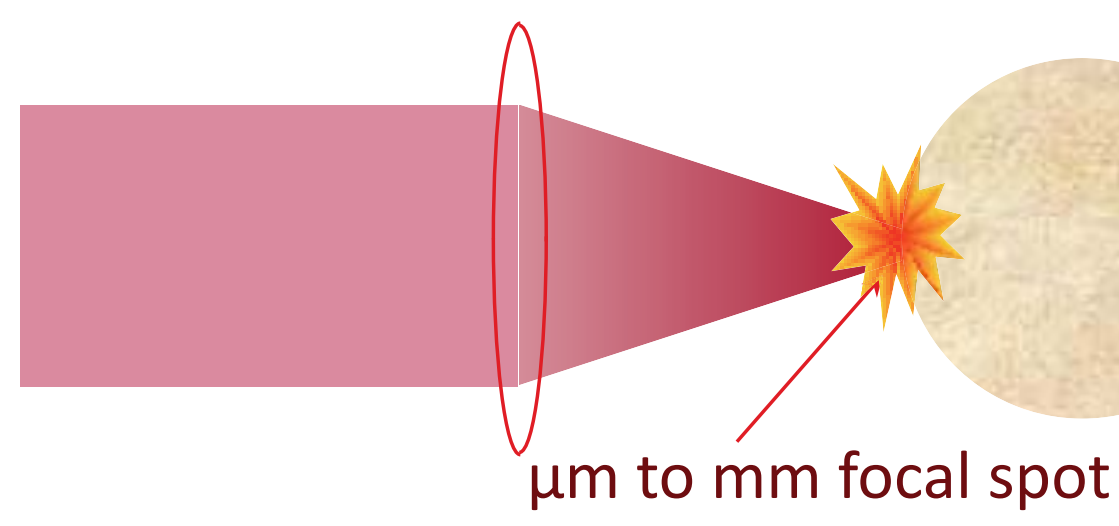

Extreme $E$ and $B$ fields $\quad 10^{12} \mathrm{~V} / \mathrm{m}-10^{5} \mathrm{~T}$ 
Hot and dense matter relevant to ...

Energy production in the sun $15000000^{\circ}$

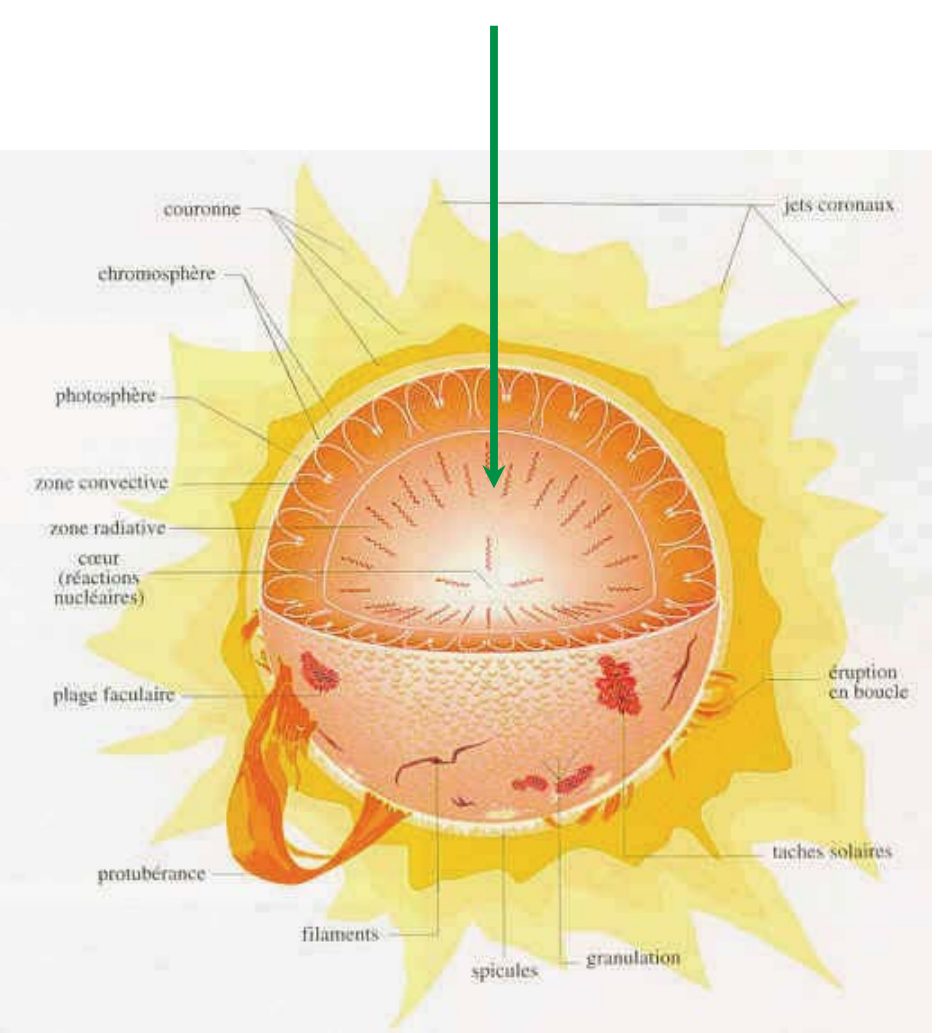

Structure of planetary cores

Millions of atmospheres

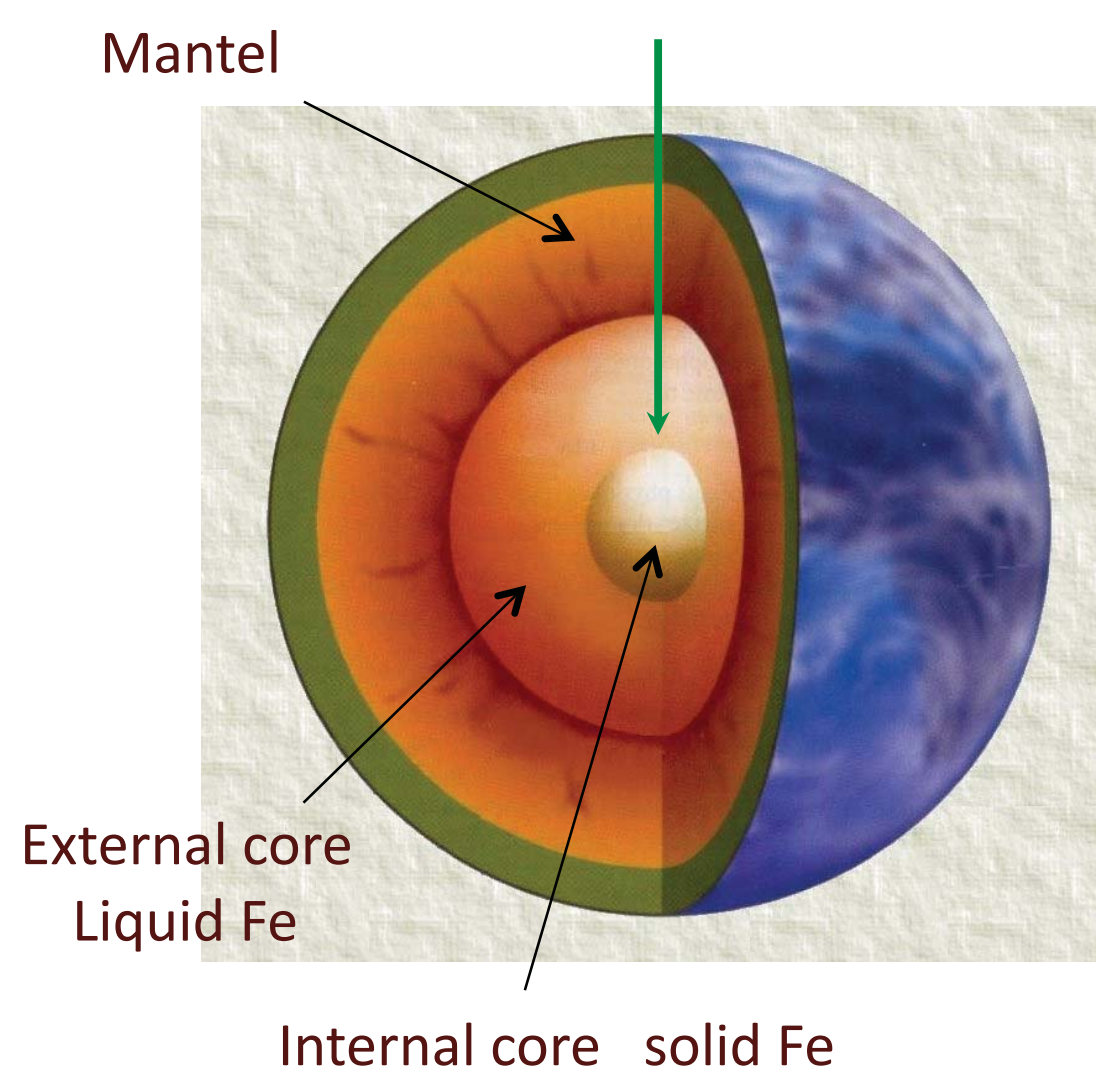


Access to the domain of high-energy density

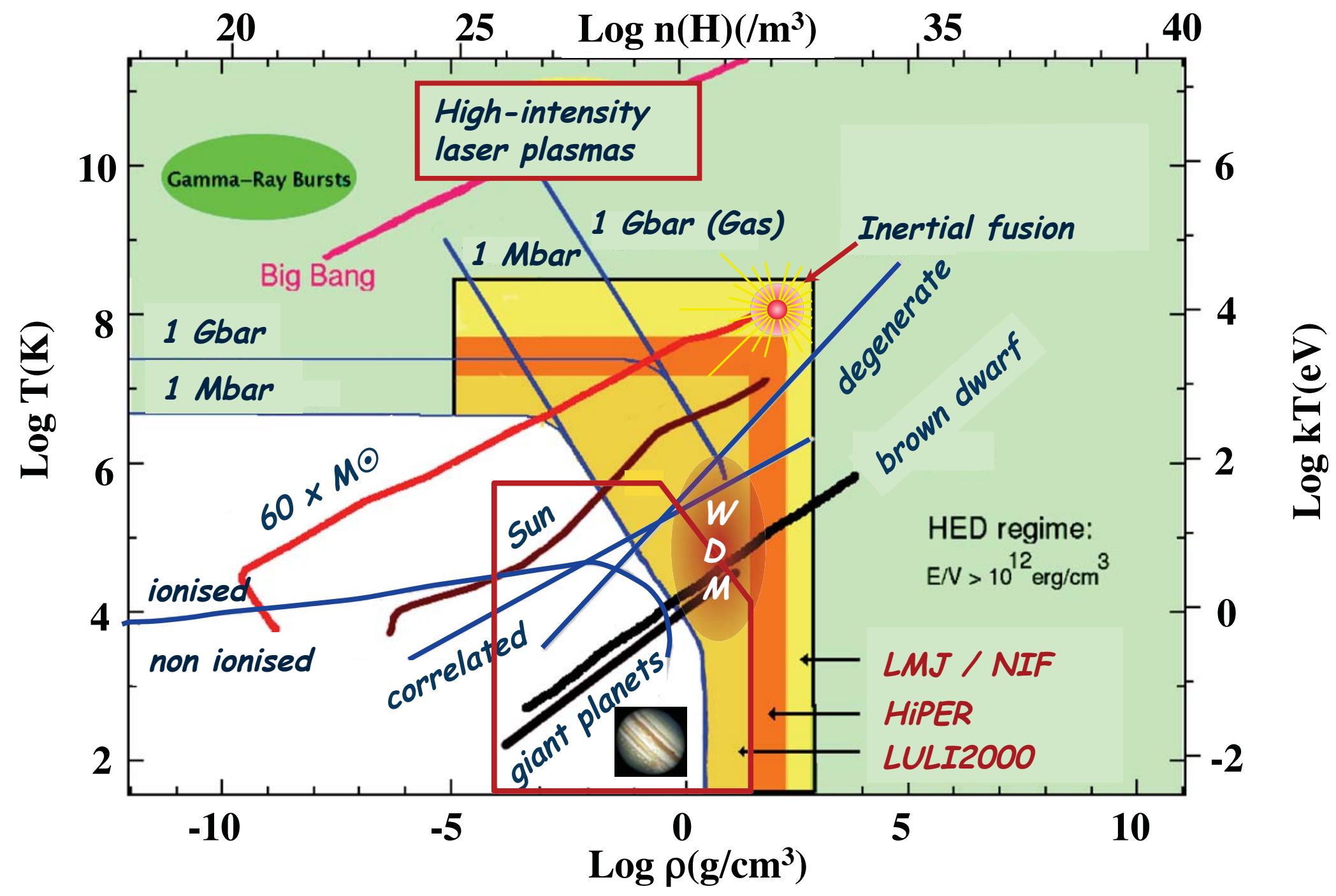

NRC Report, "Frontiers in HEDP," Ron Davidson et al. (2003) 
Intense fields to accelerate particles ...

\section{Acceleration of $\mathrm{GeV}$ electrons over few $\mathrm{mm}$}

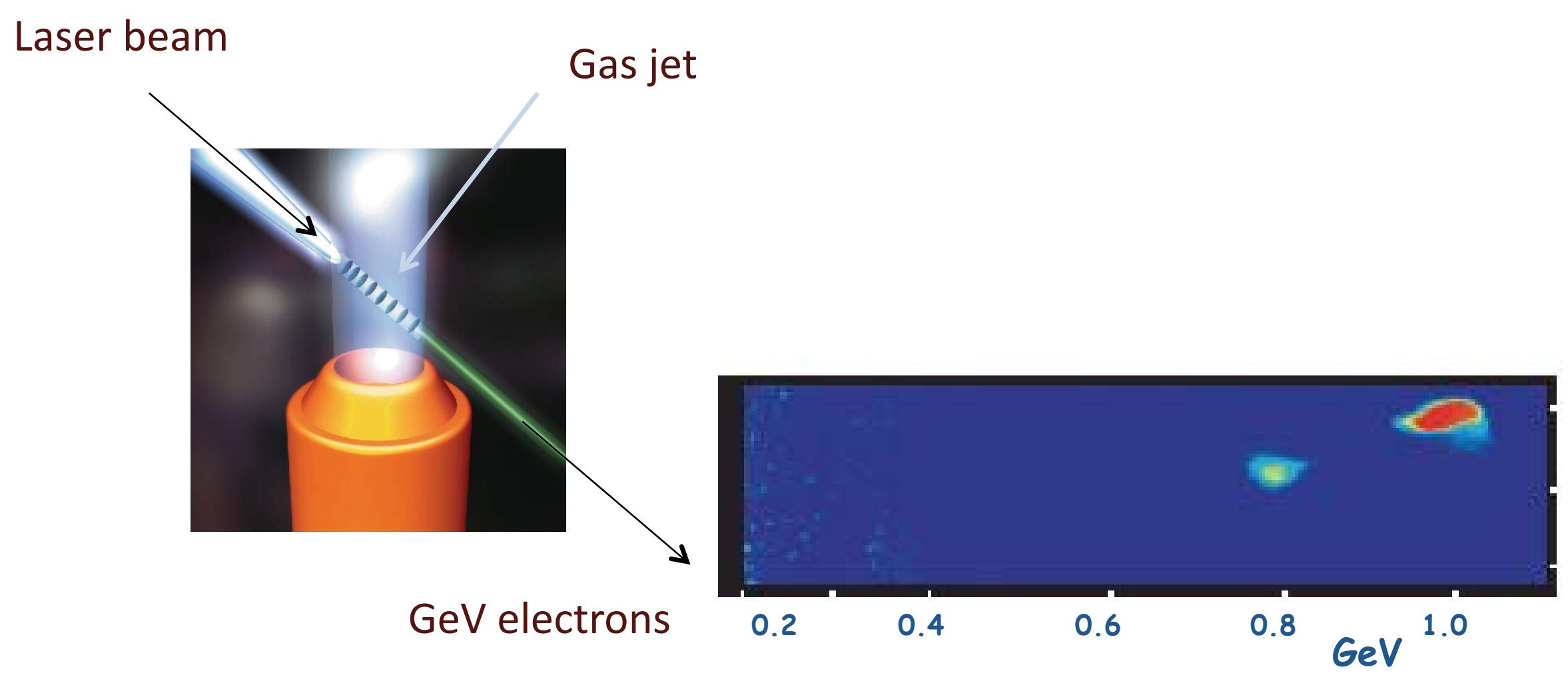

W.P. Leemans et al., Nature Physics 2, 696 (2006) 
Three families of laser systems for complementary applications

Illustration with the French panorama

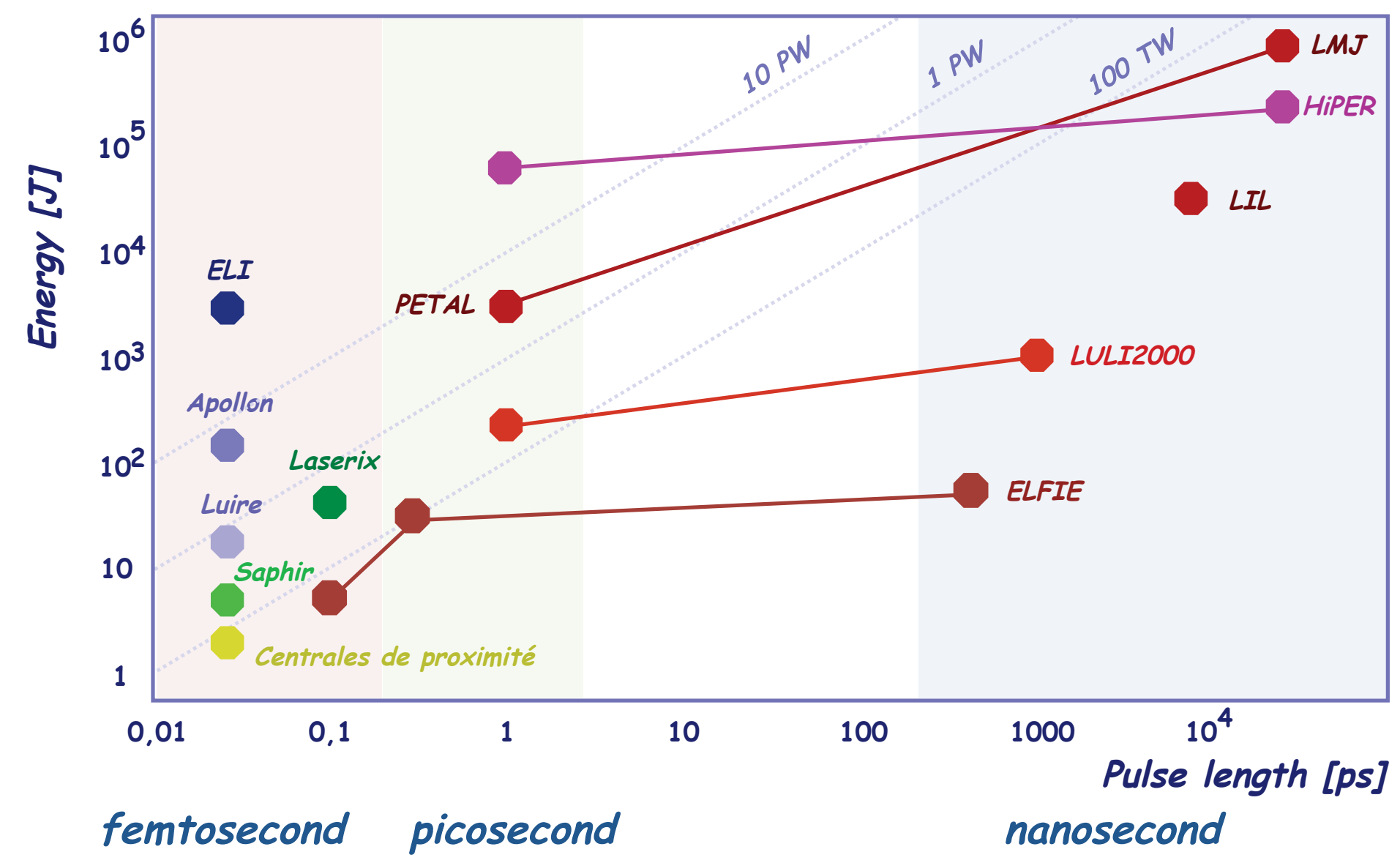


Nanosecond family - Nd:glass amplifiers up to $400 \mathrm{~mm}$

from $1 \mathrm{~kJ}$ - tennis court size
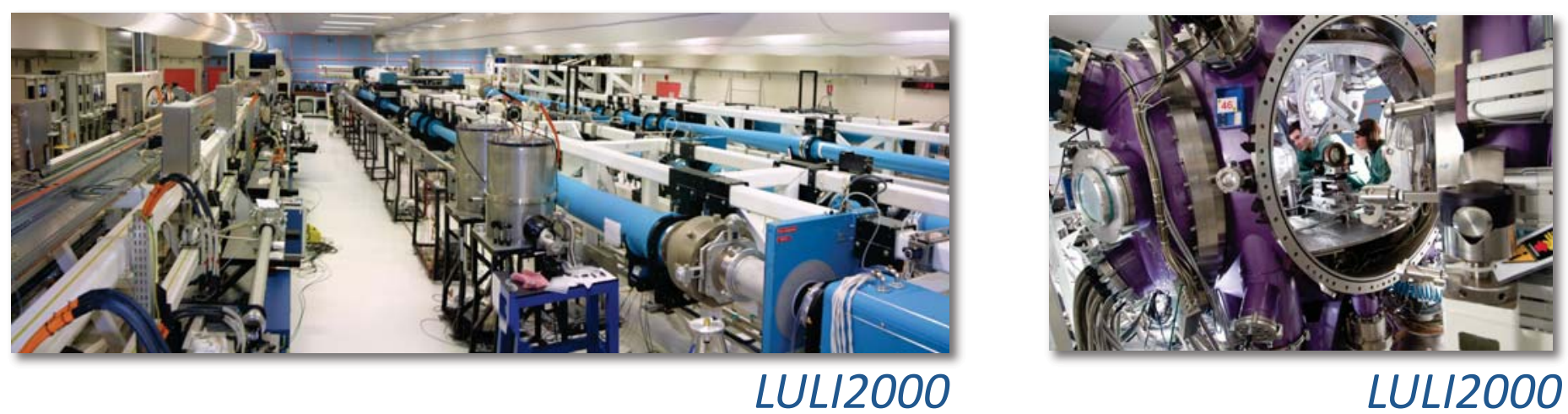

to $\quad$ MJ - Eiffel tower size
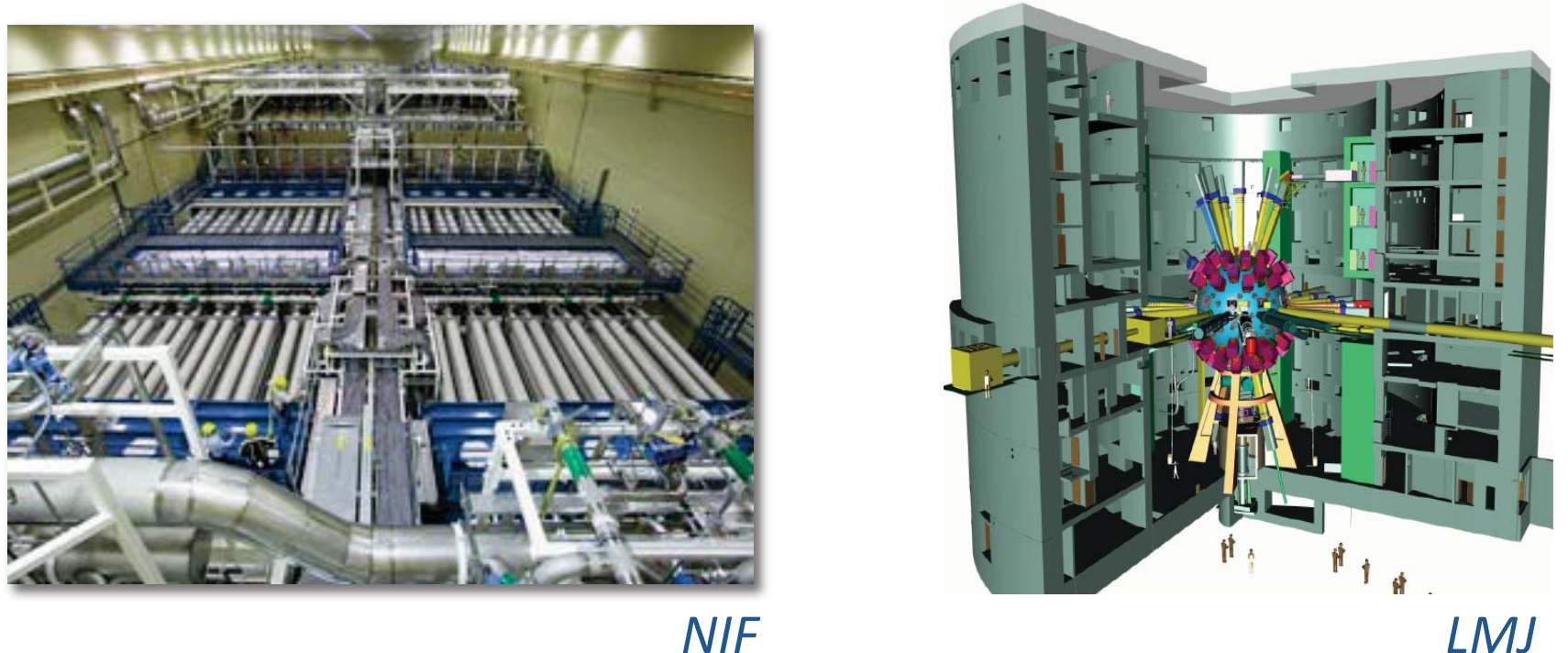

NIF

$L M J$ 
Picosecond family - chirped-pulse amplification $\mathrm{Nd}$ :glass amplifiers up to $400 \mathrm{~mm}$
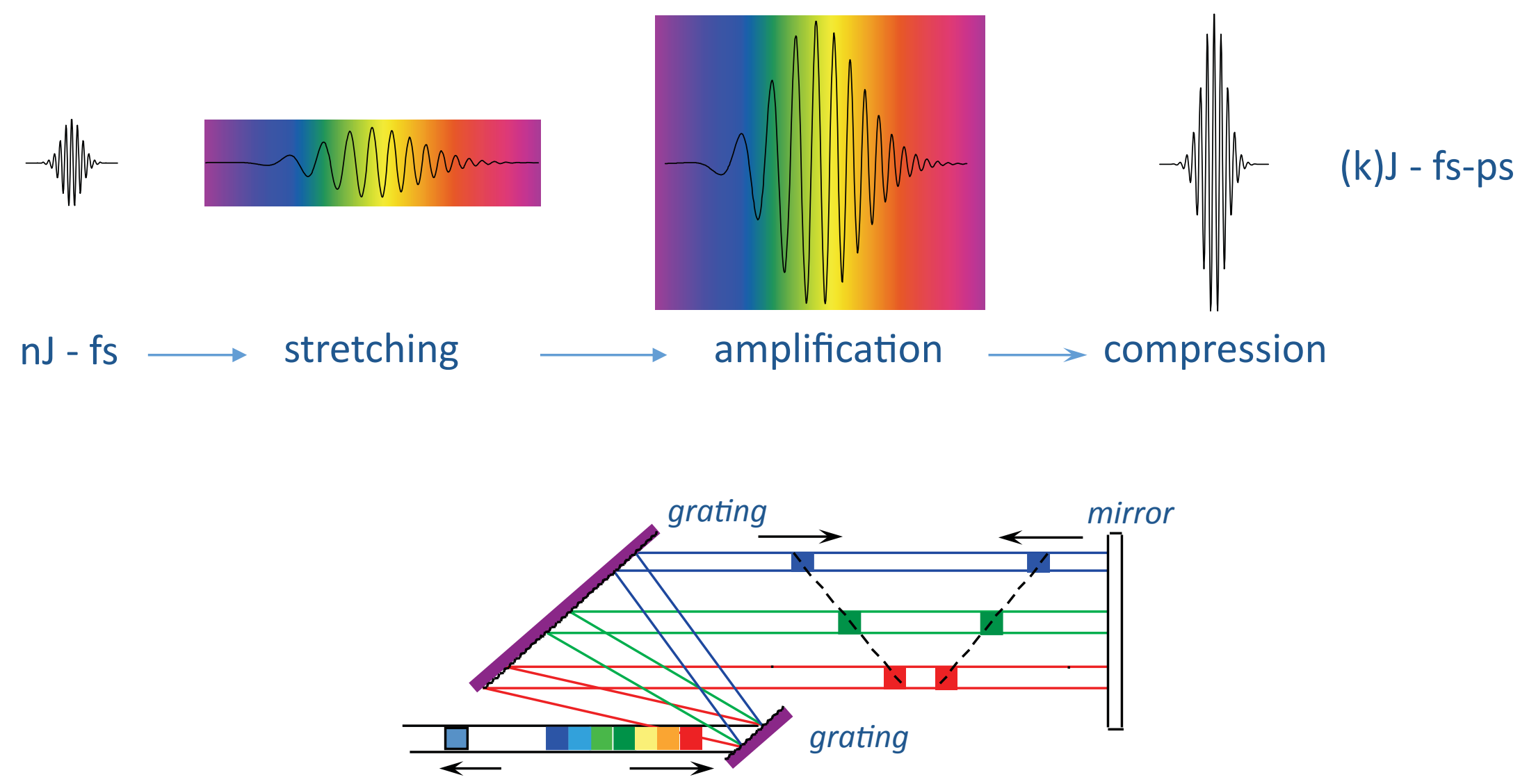

short-pulse output

chirped-pulse imput

grating compression stage 
Picosecond family - Nd:glass amplifiers up to $400 \mathrm{~mm}$

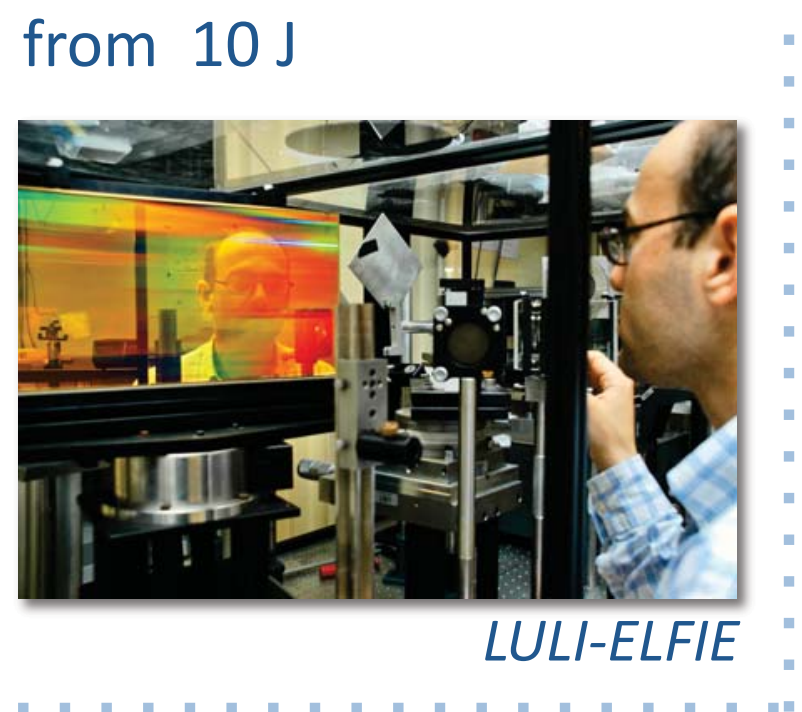

to $\mathrm{kJ}$

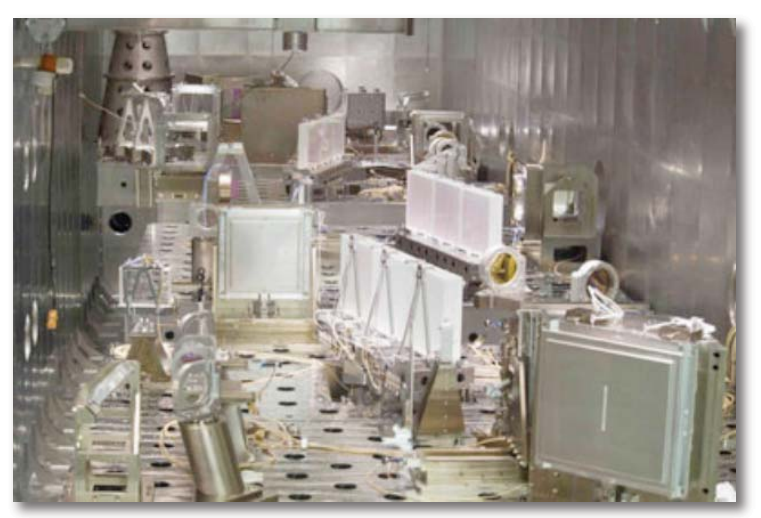

$\Omega-E P$
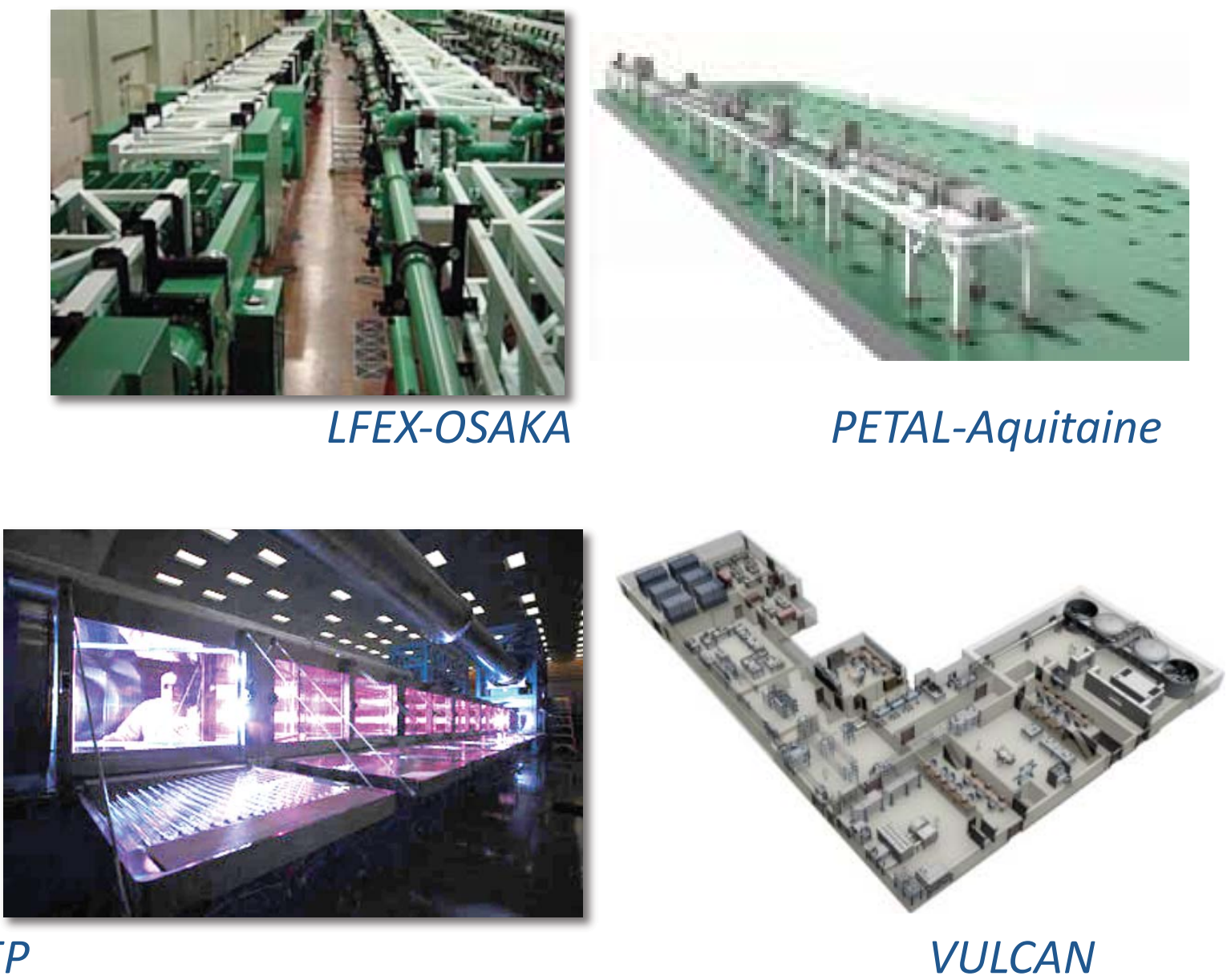
Main ns-ps laser facilities

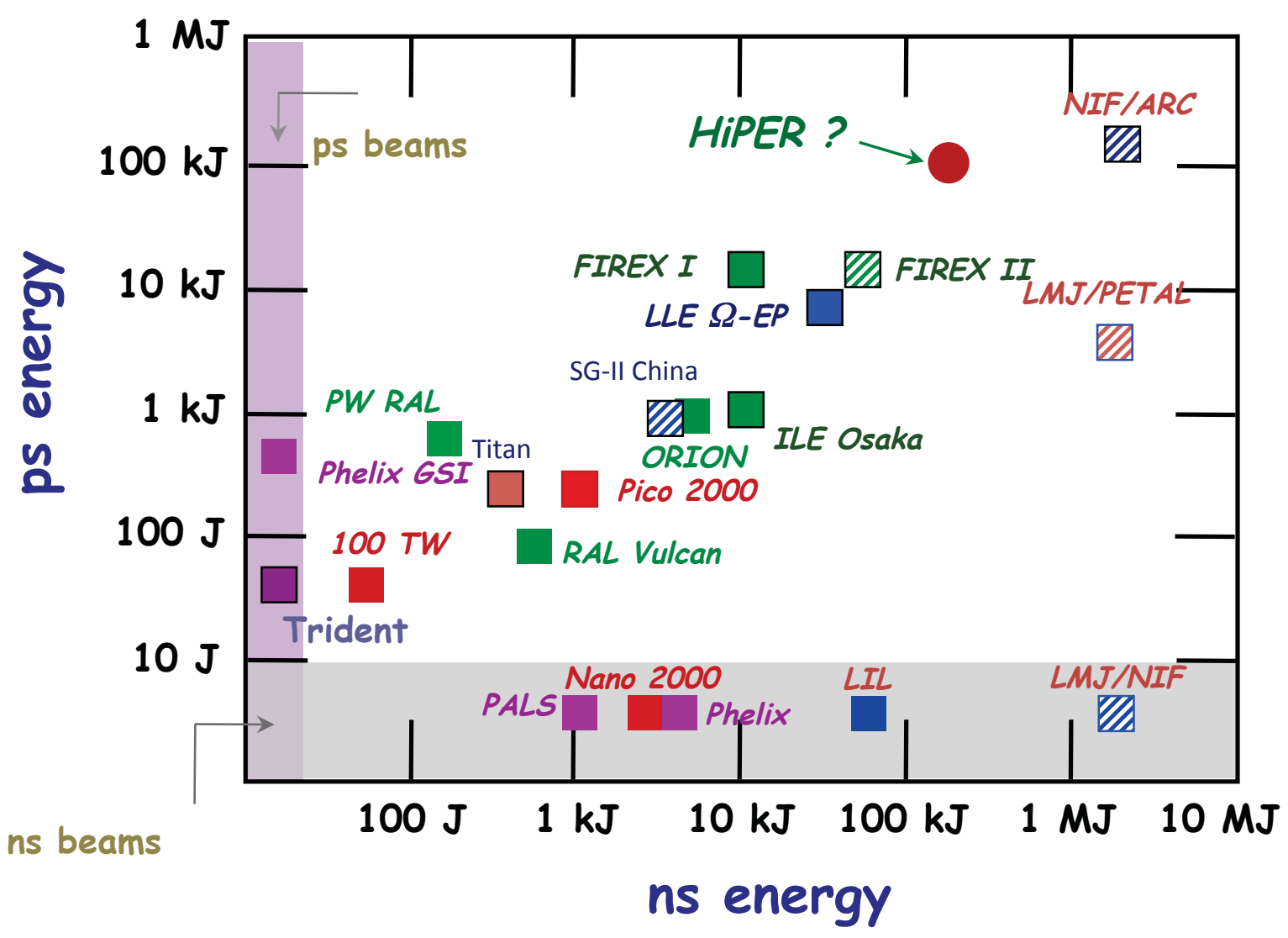


Femtosecond family - Ti:Sa amplifiers up to $150 \mathrm{~mm}$

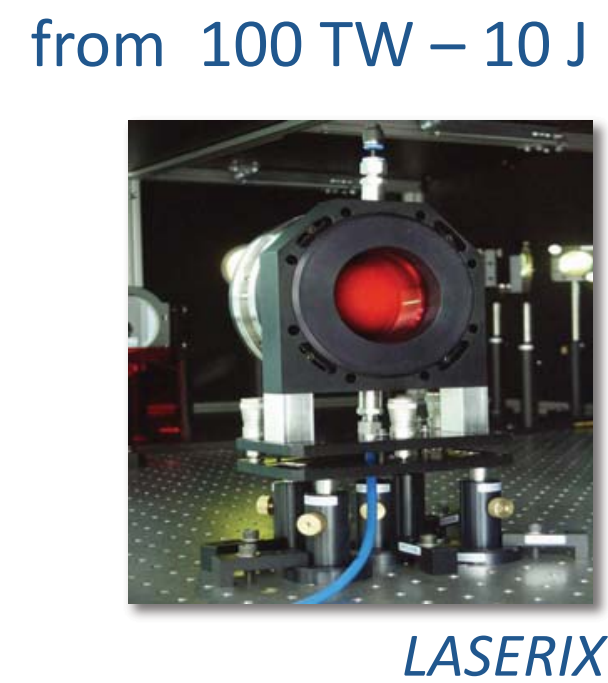

to PW

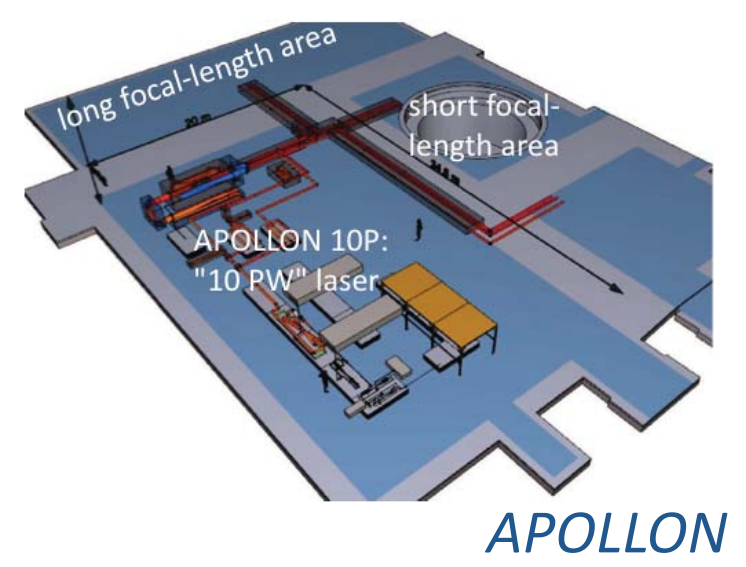

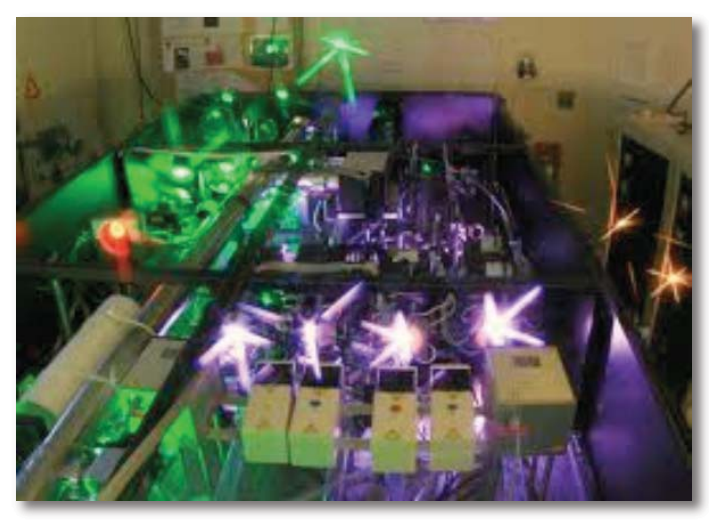

HERCULES
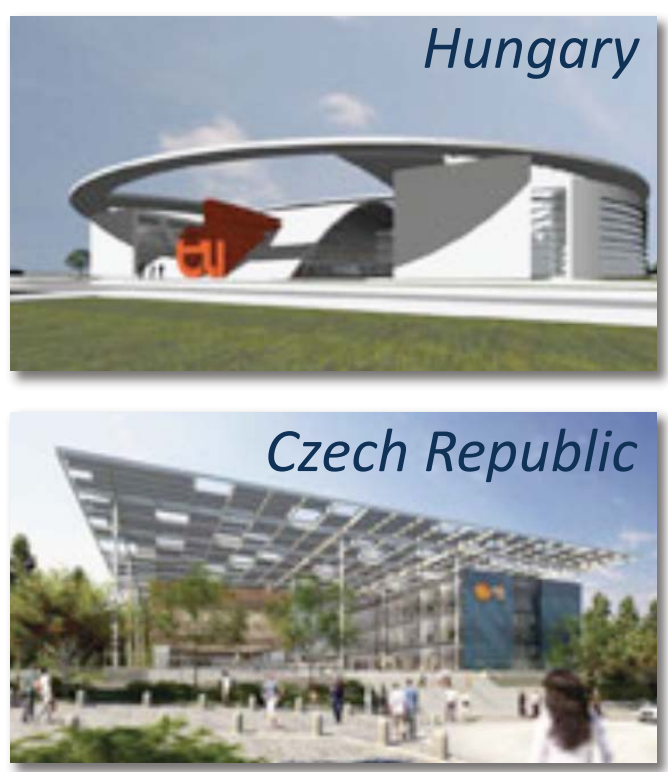

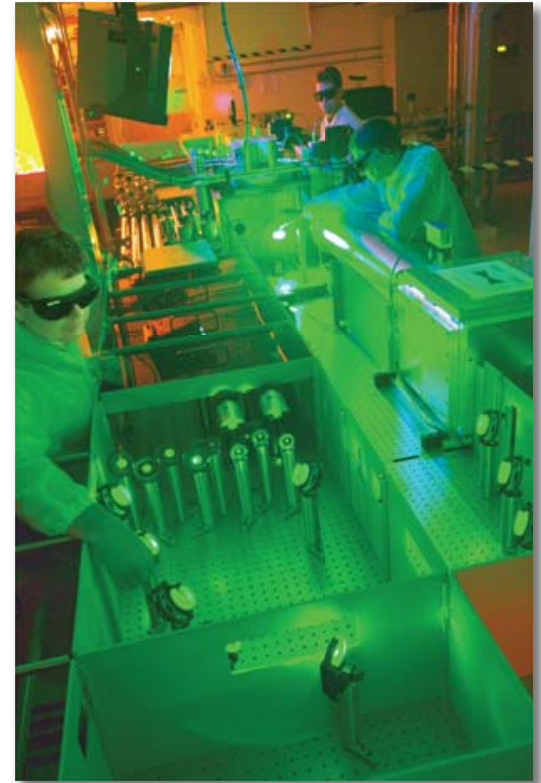

TREX - LBNL

$E L I S$

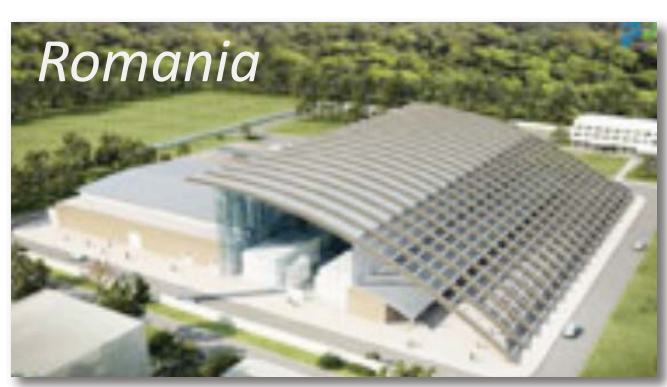




\section{CILEX- APOLLON}

\section{General objective}

Develop CILEX

a Research Centre on Intense Lasers, Plasmas and Applications

hosting the most powerful lasers

APOLLON 10P

and smaller scale facilities

CILEX-PHAC

for pluridisciplinary programs

and training of scientists

and engineers

Operated as a user-facility

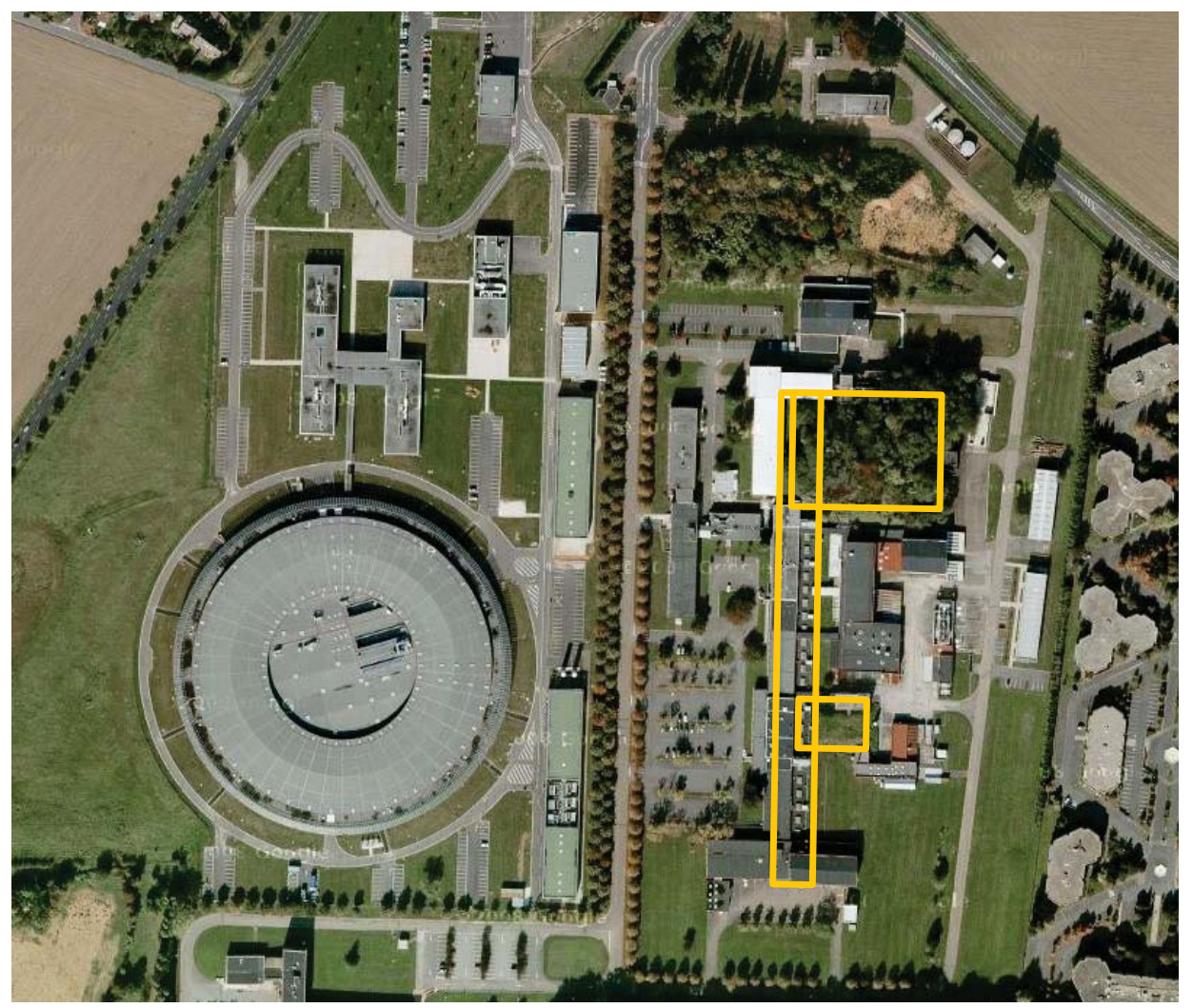


Three scientific domains in the high-intensity regime

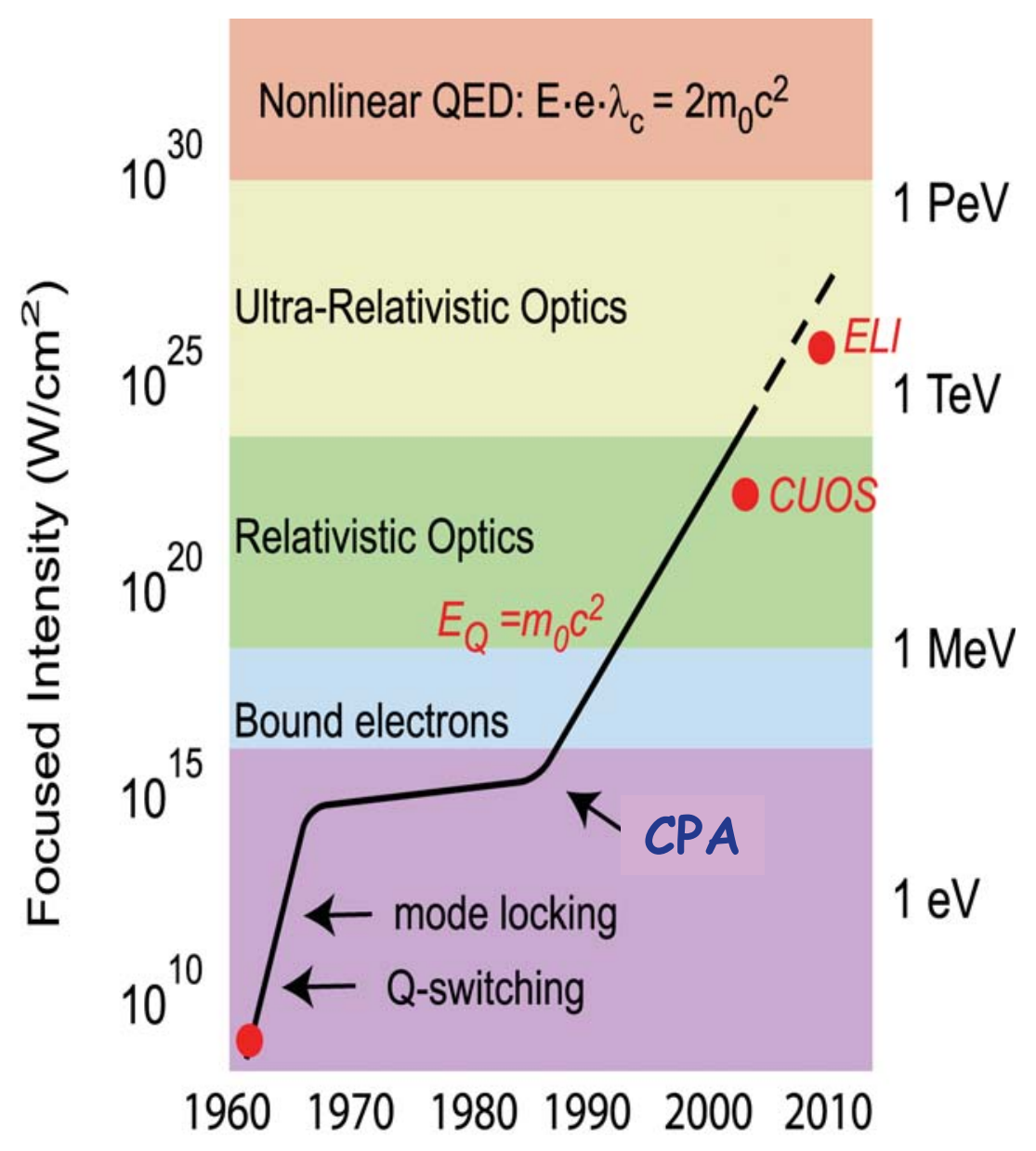

Science at ultra-high intensity ultra-relativistic regime particle physics field theory ...

Attosecond science attosecond scale imaging electron dynamics in atoms, molecules, plasmas or solids

High-energy beams ultra short beams of energetic particles (>10 GeV) and radiation $\rightarrow \gamma$ and applications 
At high intensity, laser-matter interaction produces high-energy $\mathrm{e}^{-}$

At high intensity $v \times B$ term accelerates electrons forward with $v \approx c$
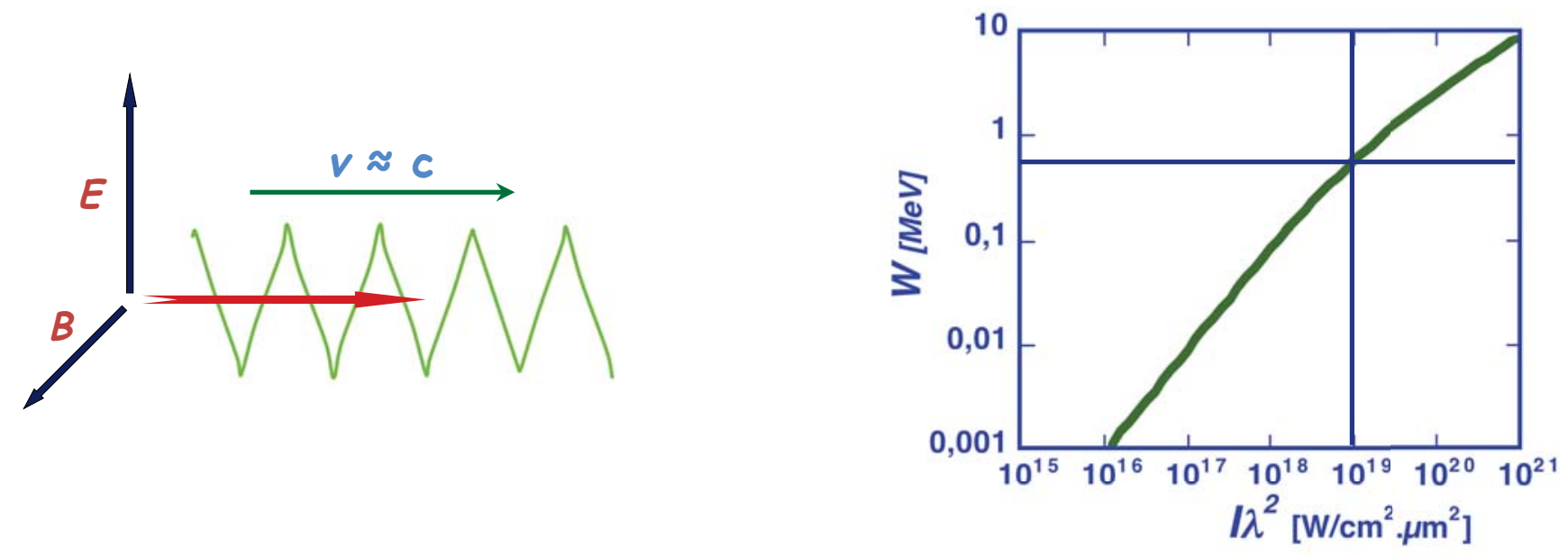

On solid targets $E$ or $v \times B$ injects electrons at $\omega$ or $2 \omega$
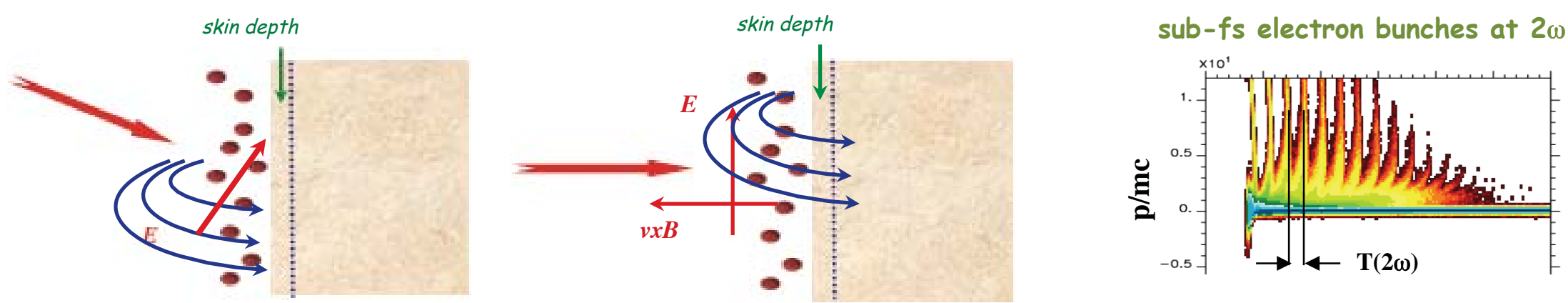

H. Popescu et al., Physics of Plasmas 12, 063106 (2005) 


\section{Laser-matter interaction as a photon - electron transformer ...}

\section{Selit}

A large fraction of laser energy converted to high-energy electrons

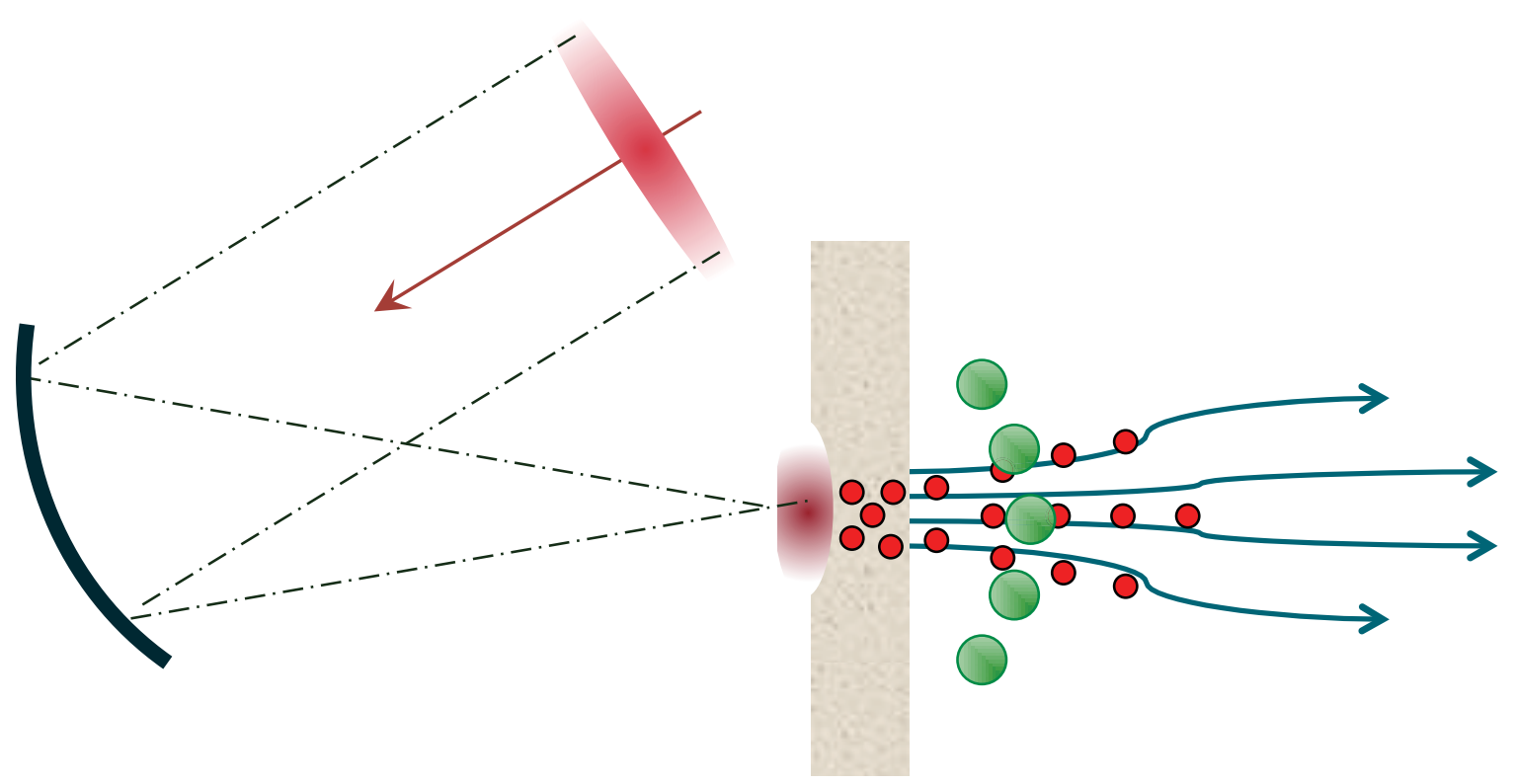


The parameters of the electron beams are extreme and physics is complex

Order of magnitude for $1 \mathrm{~J}$ and $1 \mathrm{MeV}$

$$
Q \approx \mu C, \tau<\mathrm{ps}, \Phi \approx 10 \mu \mathrm{m}, I>10^{6} \mathrm{~A}, j \approx 10^{11} \mathrm{~A} / \mathrm{cm}^{2}
$$

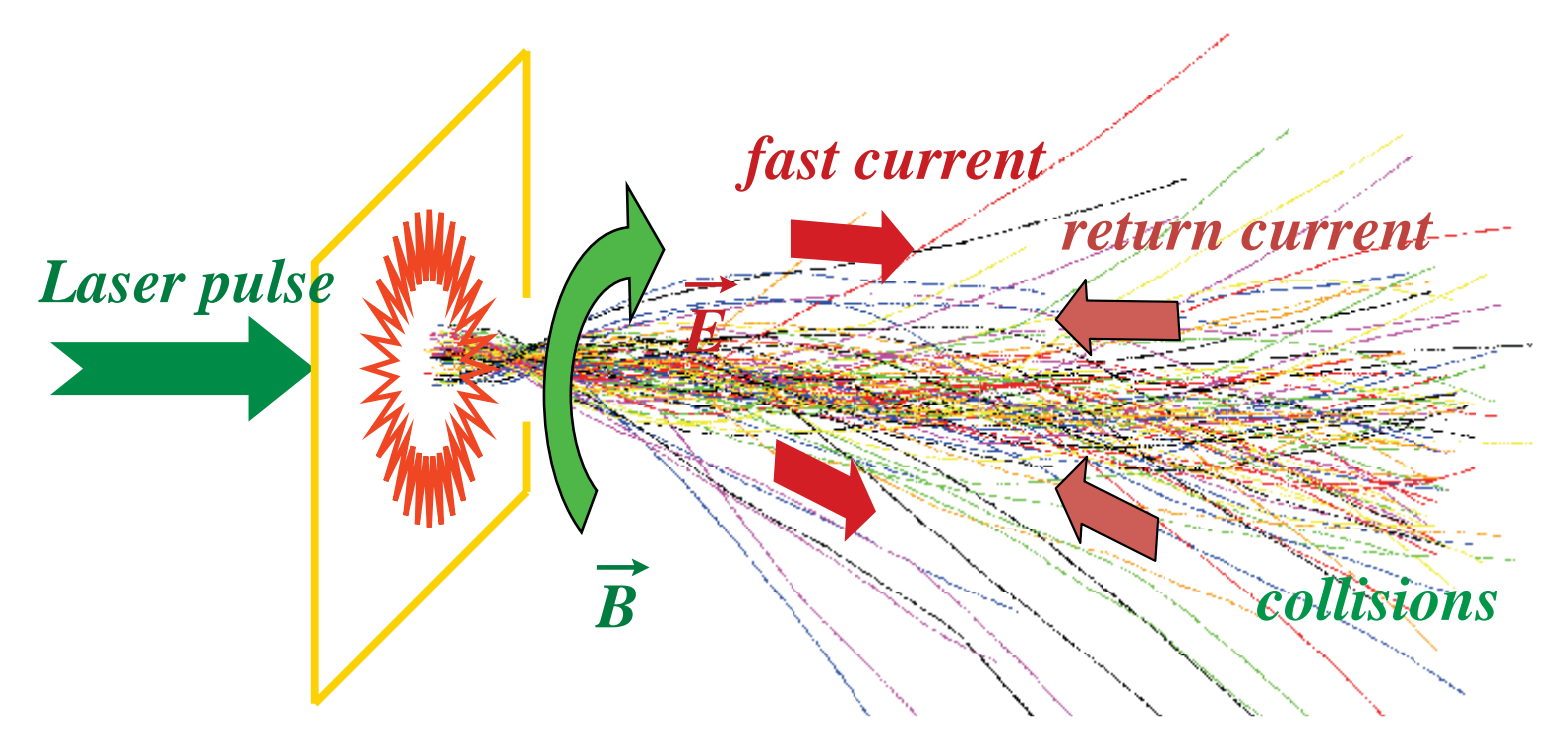

Space charge effects

Induced fields: return current, focusing, guiding

Instabilities : Weibel, filamentation, coalescence, ...

Collisions: slowing down, scattering 
Accelerated electrons induce high E-field accelerating ions

\section{符}

today : small fraction of electrons ejected

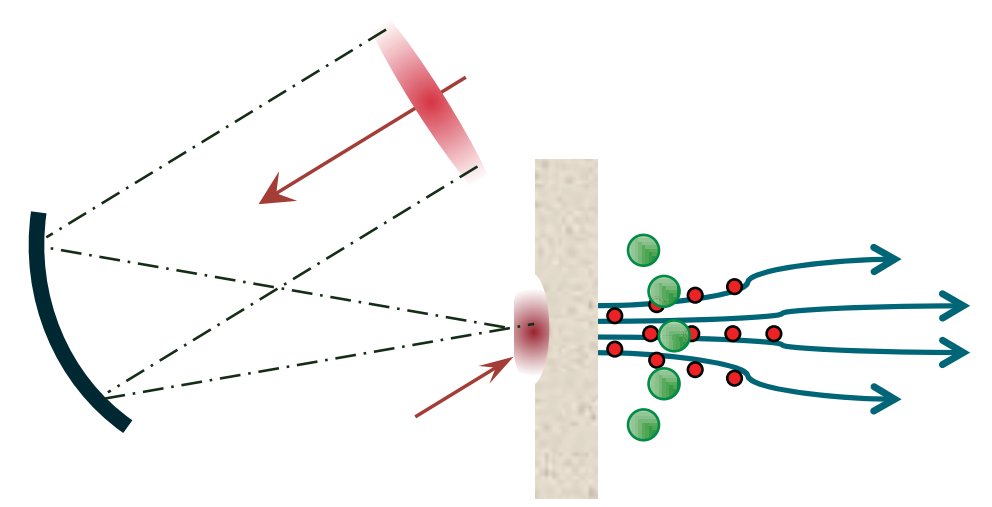

\section{present record: $\quad$ protons $\approx 100 \mathrm{MeV}$}

tomorrow : expulsion of all electrons inside focal spot

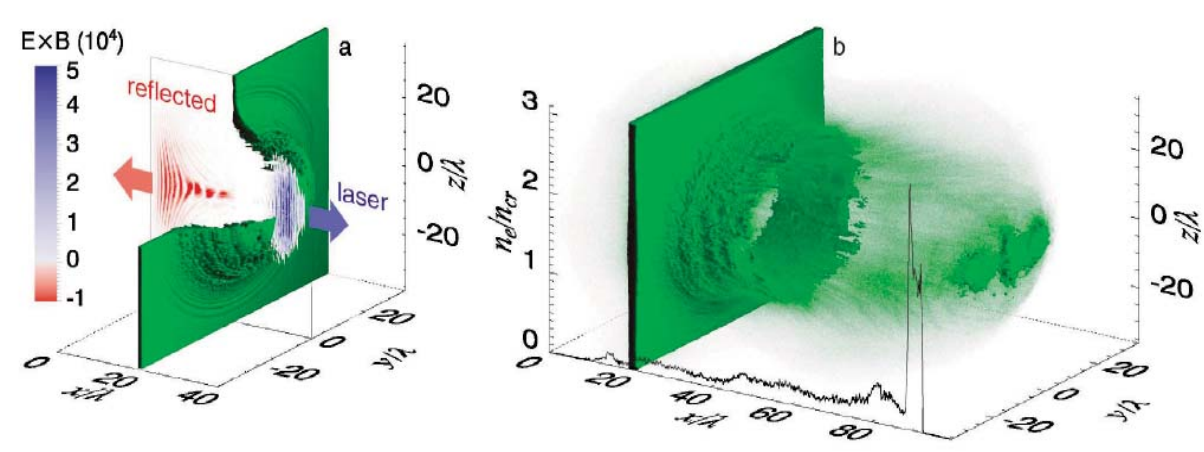

multi-GeV protons

T. Esirkepov et al., Physical Review Letters 92, 175003 (2004) 


\section{Laser electron acceleration: toward high energies}

\section{Acceleration to high energies - $\mathrm{TeV}$ ?}

multistage acceleration

quality, stability of beams

example of 2 possible injector+accelerator setup schemes

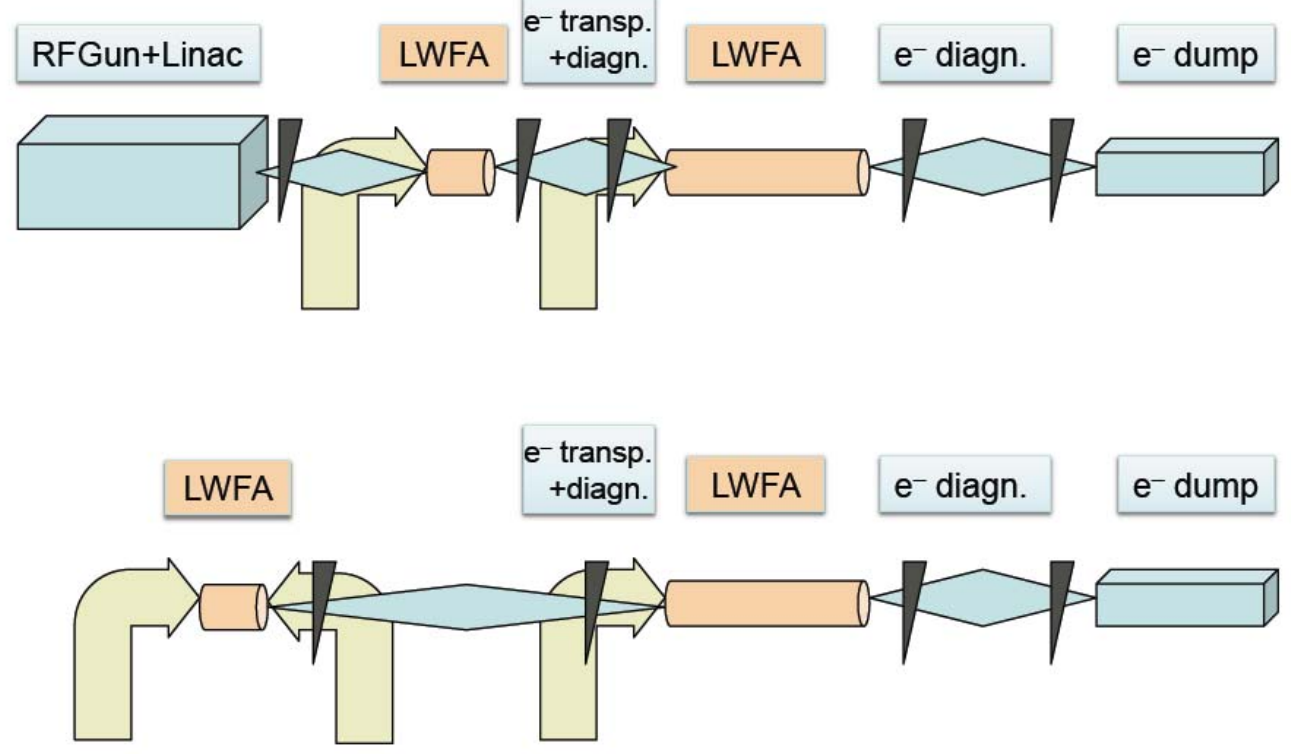


Laser beams - a variety of generation mechanisms of intense and collimated $X$ and $\gamma$-ray beams

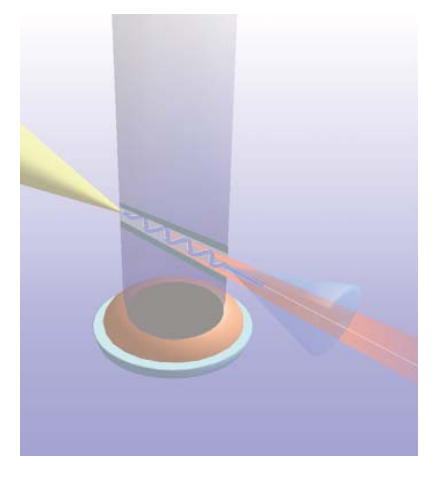

Betatron emission: electrons inside the plasma

Free-electron laser: electrons + undulator

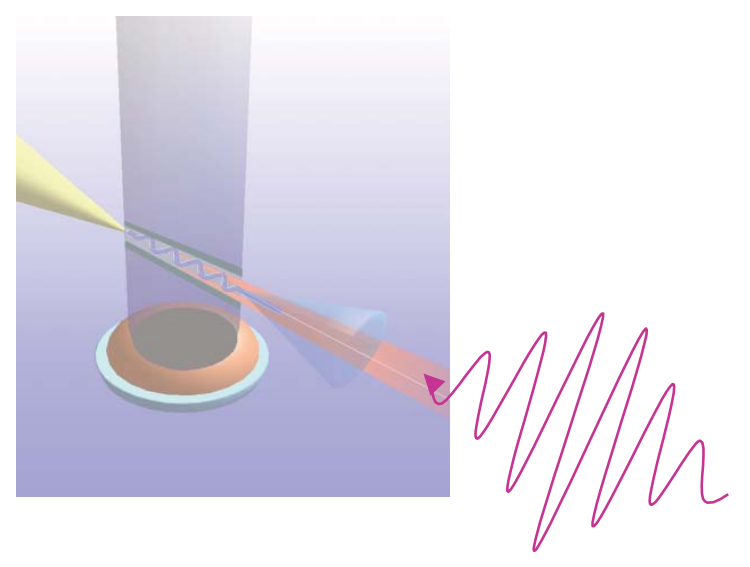

Compton scattering: electrons + laser

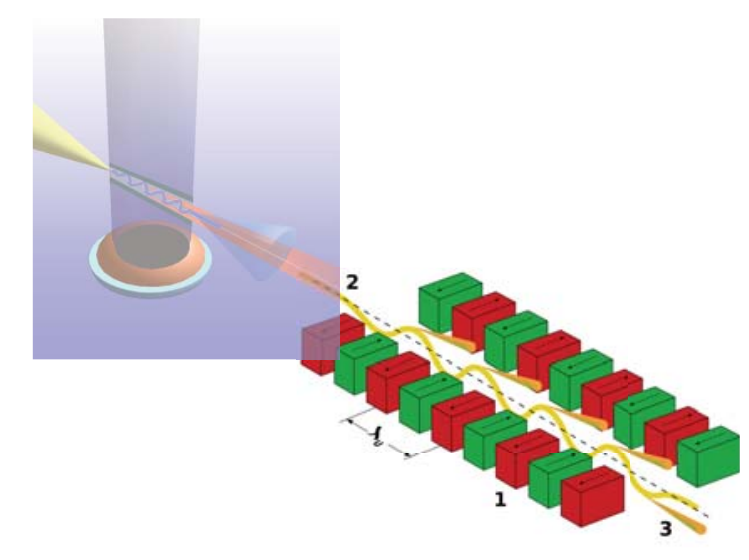




\section{The interesting case of electron beam - laser beam interaction}

In its rest frame, the electron sees a frequency $\approx 2 \gamma \nu$

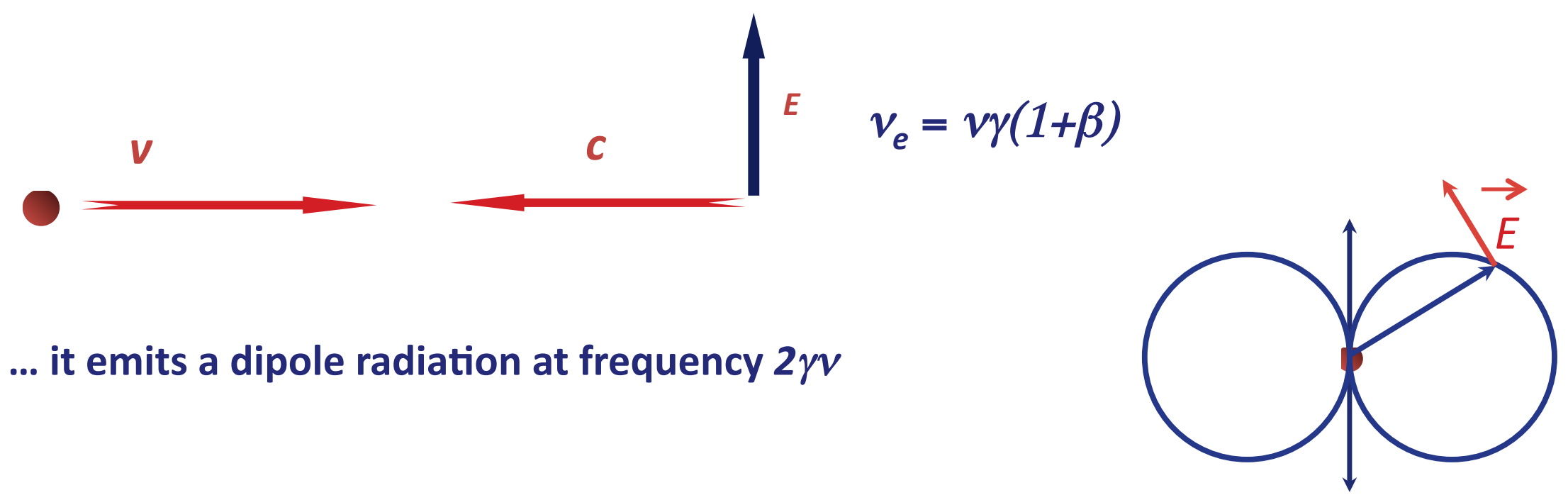

... back to the lab frame it emits at frequency $4 \gamma^{2} v$

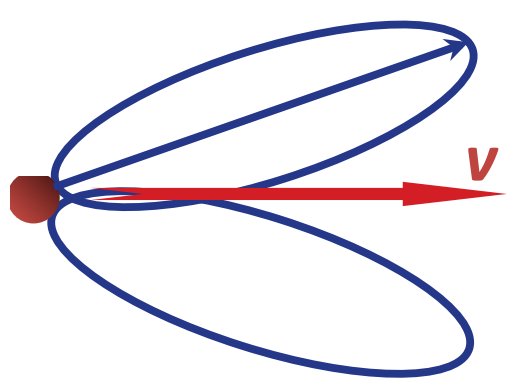


High-order harmonics, attosecond pulses

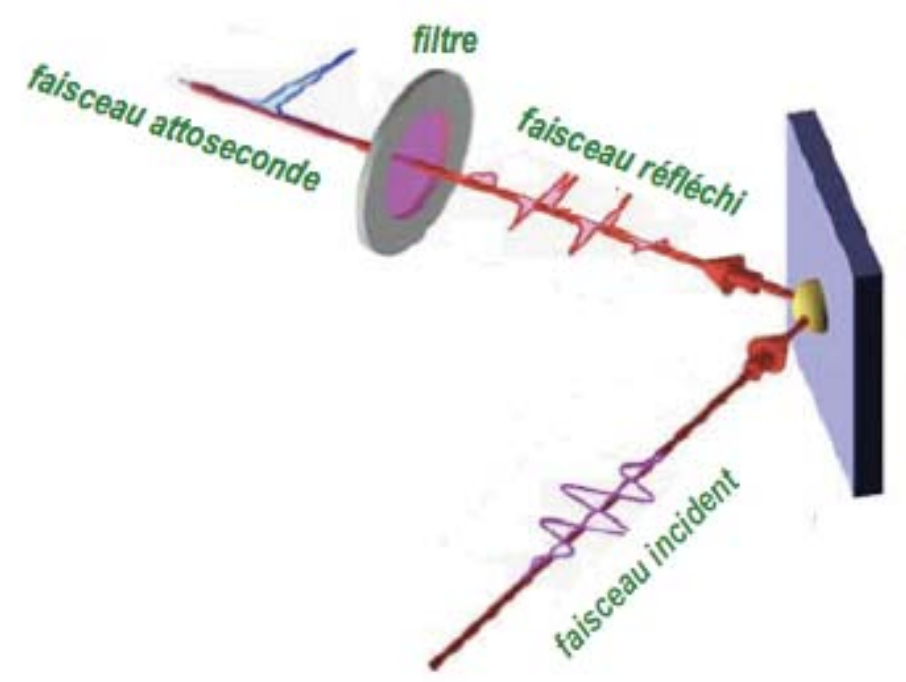

Simulations predict wide enough spectra for attosecond to zeptosecond pulses

80 as already demonstrated

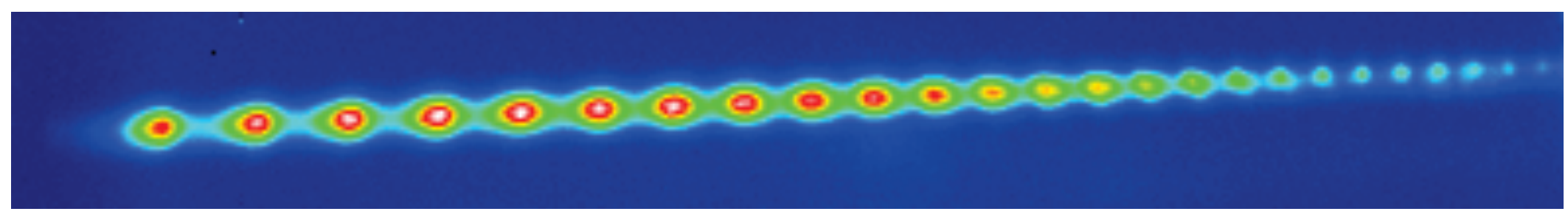


Laser fields separates virtual electron and positron

Condition:

separate the 2 particles by Compton length during lifetime

or transfer energy $2 m c^{2}$ with $E_{\text {laser }}$
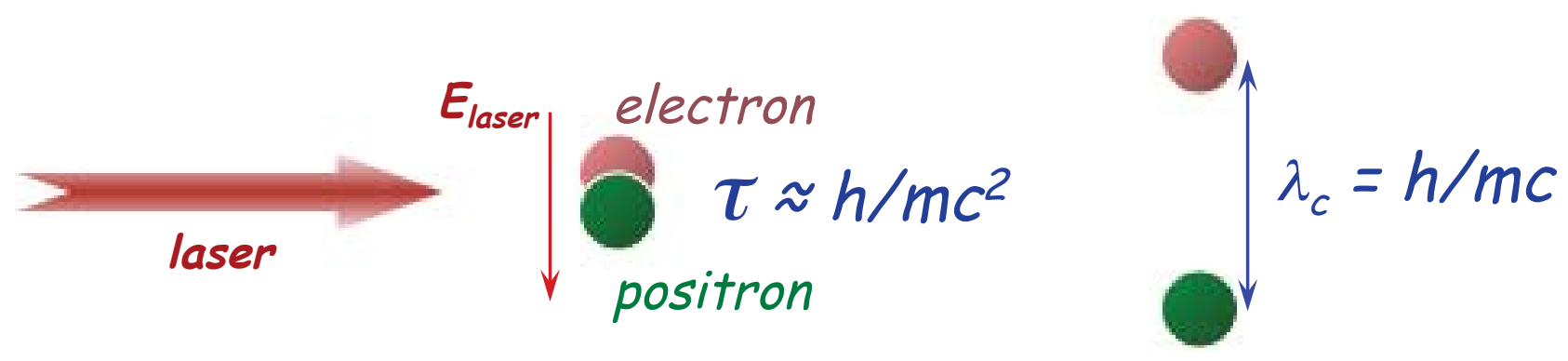

$$
e E \lambda c_{c} /(2 \pi)^{2}>2 m c^{2}
$$$$
I>10^{29} \mathrm{~W} / \mathrm{cm}^{2} \cdot \mu \mathrm{m}^{2}
$$

We are very very very far from it ... ... but nice physics can be studied below this limit (cf. M. Marklund) 
My own experience on strange physics (for a plasma physicist !!) Light shining through the wall (C. Robilliard et al.)

C. Robilliard et al., PRL 99, 190403 (2007)

Search for axions by light shining through the wall
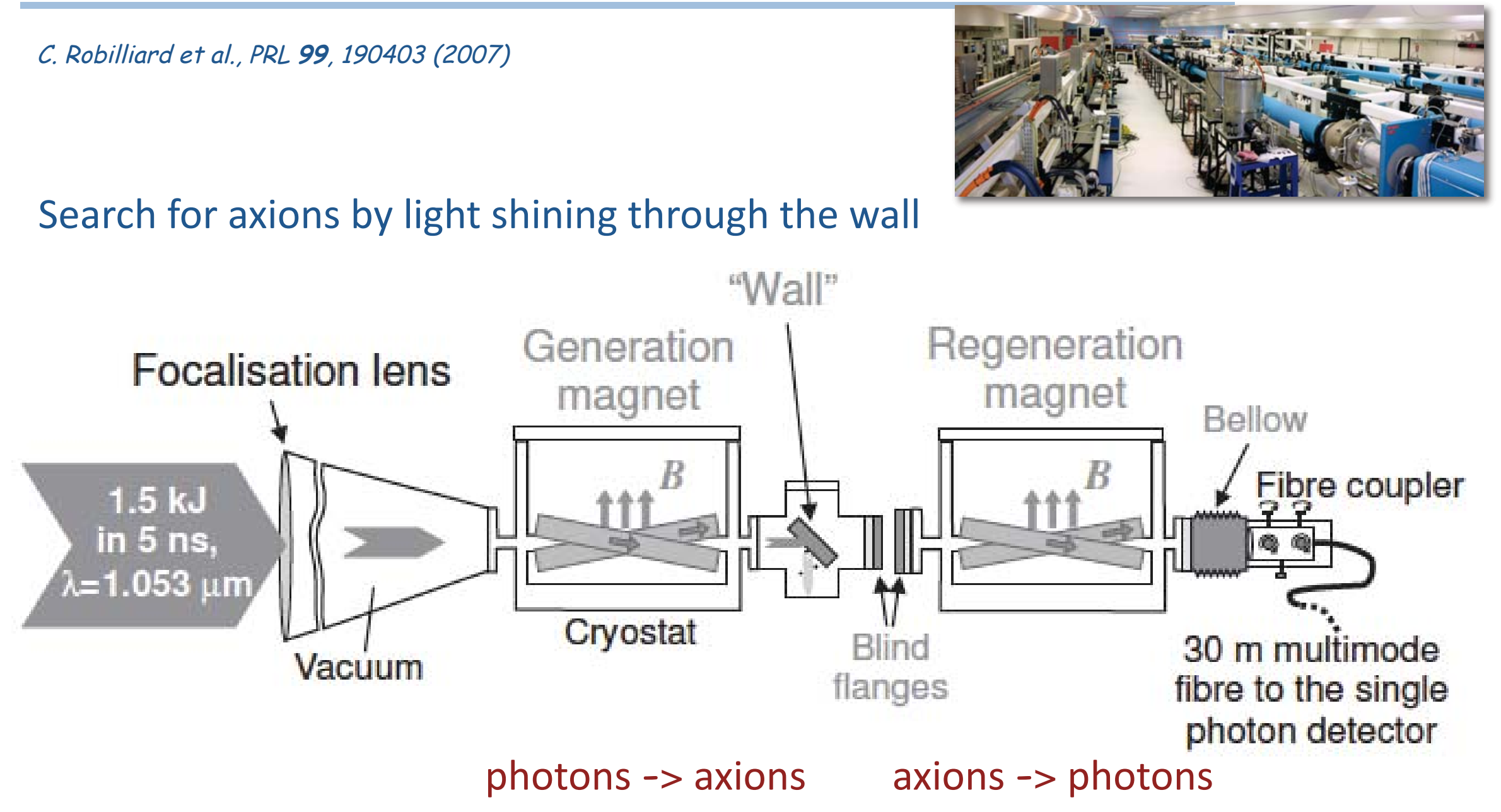

Or: How to be sure your result is correct? 
My own experience ... (2)

Stimulated photon scattering at a cms energy of $0.8 \mathrm{eV}$ (D. Bernard, F. Moulin, F. Amiranoff)

$40 \mathrm{fs}, 4-6 \mu \mathrm{m}$ focal spots

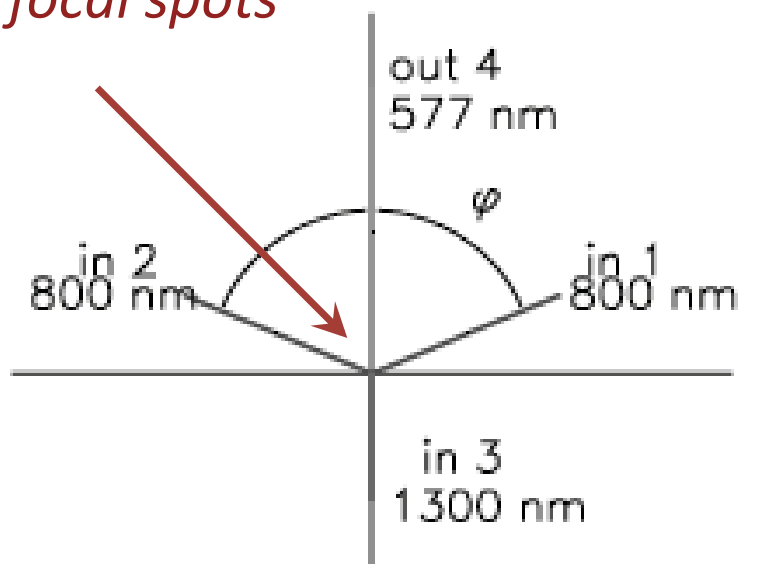

Detection of scattered photons?

Collision between $3 \mathrm{fs}$ beams in vacuum

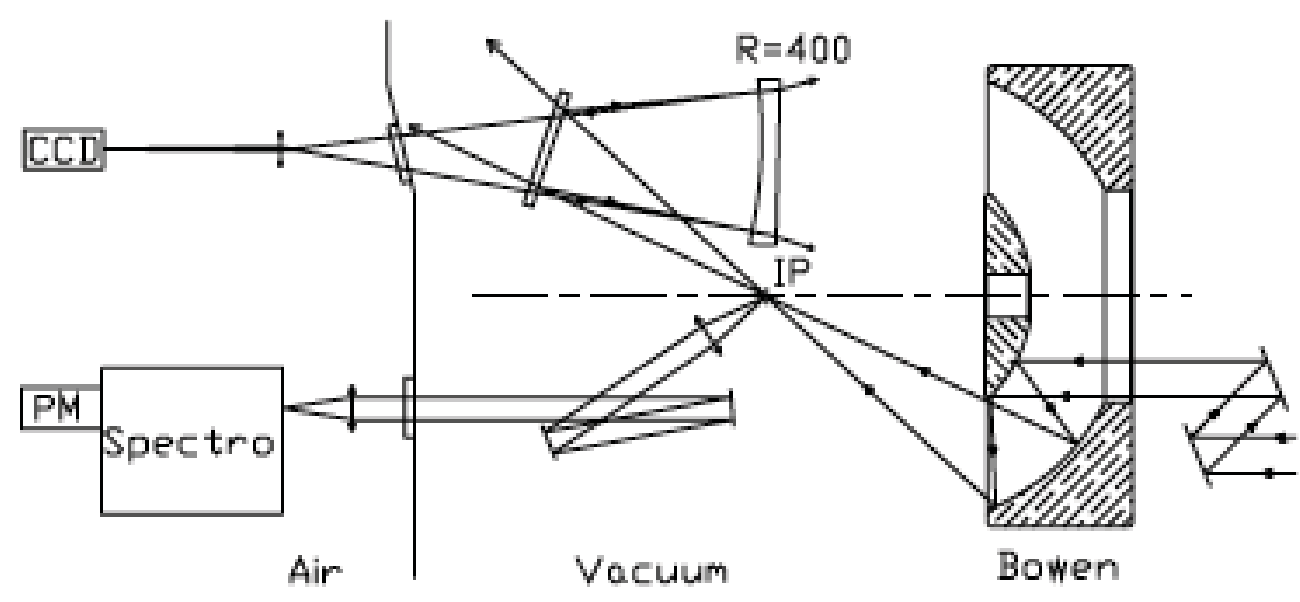

$$
\sigma<10^{-48} \mathrm{~cm}^{2} \text { - still } 18 \text { orders of magnitude from QED }
$$

Or: How to be sure your result is correct? 


\section{A few characteristic parameters}

All values for

$$
1 \mathrm{~J}-3 \mathrm{fs}-1 \mu \mathrm{m}^{2} \text { at } 1 \mu \mathrm{m} \text { wavelength }
$$

$$
\begin{array}{r}
\mathrm{I} \approx 310^{22} \mathrm{~W} / \mathrm{cm}^{2} \\
\mathrm{n}_{\mathrm{ph}} \approx 10^{31} \text { photons } / \mathrm{cm}^{3}
\end{array}
$$

in beam-beam collisions $\approx 1$ event for $\sigma>10^{-46} \mathrm{~cm}^{2}$

$$
\begin{aligned}
& \text { energy density } \approx 10^{12} \mathrm{~J} / \mathrm{cm}^{3} \\
& \mathrm{E} \approx 5 \cdot 10^{14} \mathrm{~V} / \mathrm{m} \\
& 50 \mathrm{kV} / \AA \\
& 0.5 \mathrm{~V} / \mathrm{fm}
\end{aligned}
$$

better for you to check ... and find other parameters of interest 
Three scientific domains in the high-intensity regime

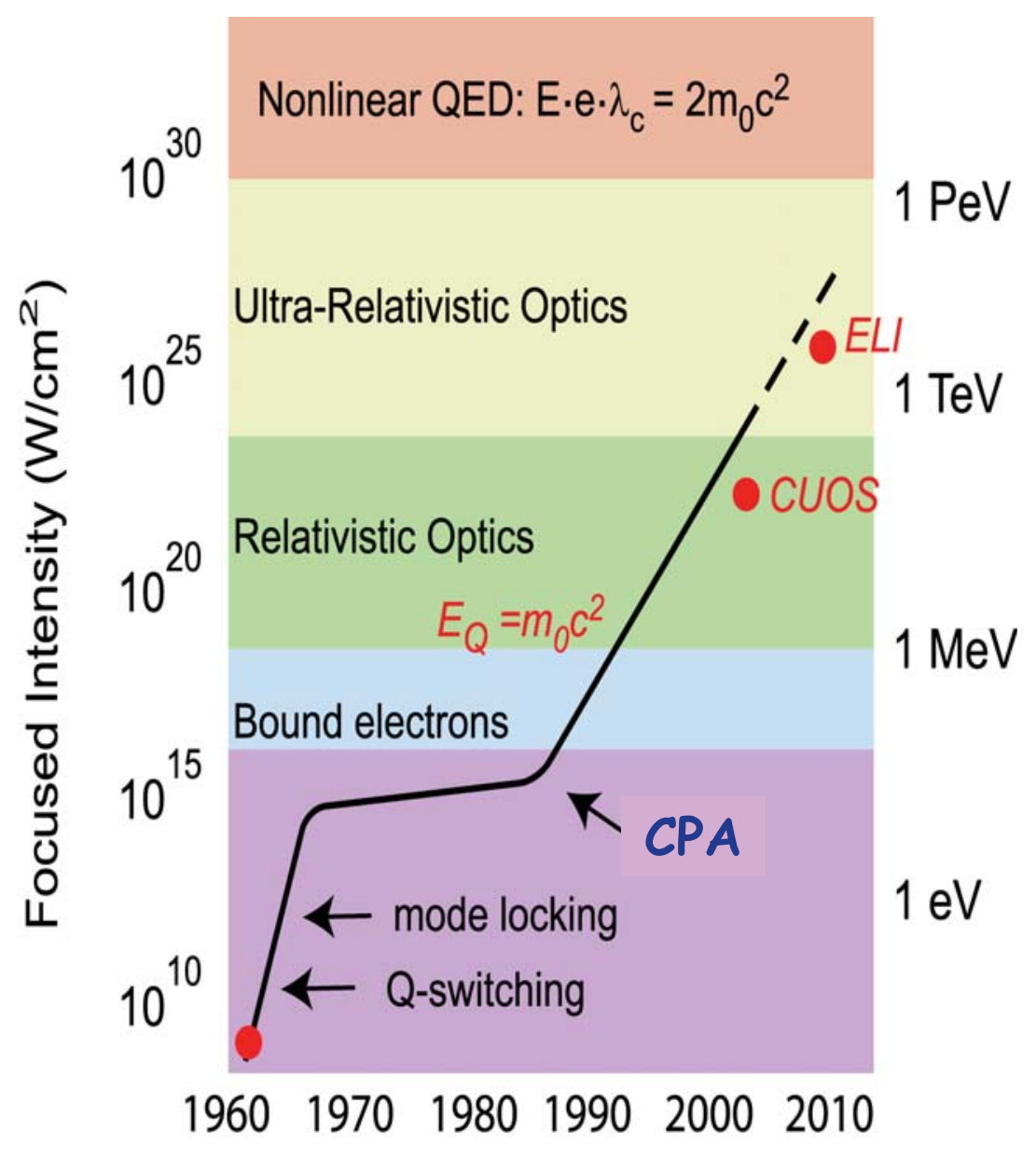

Science at ultra-high intensity ultra-relativistic regime particle physics field theory ... it's up to you now!

\section{Attosecond science}

attosecond scale imaging

electron dynamics in atoms, molecules, plasmas or solids

High-energy beams

ultra short beams of energetic particles (>10 GeV) and radiation $\rightarrow \gamma$

\section{and applications}

